\title{
Encontro de Aedes scapularis (Diptera: Culicidae) em criadouro artificial em localidade da região Sul do Brasil
}

\section{Occurrence of Aedes scapularis (Diptera:Culicidae) in artificial breeding area of Southern Brazil}

\author{
Allan M. da Silva e Regiane M. T. de Menezes \\ Laboratório de Entomologia Médica da Fundação Nacional de Saúde. Jacarezinho, PR - Brasil \\ (A.M.S.), Laboratório de Entomologia da Superintendência de Controle de Endemias. São Paulo, SP \\ - Brasil (R.M.T.M.)
}

\begin{abstract}
Resumo
Duas larvas de Aedes scapularis foram encontradas em um criadouro artificial, no Município de Sertaneja, Norte do Estado do Paraná, Brasil, durante atividade de rotina para o controle de vetores da dengue.
\end{abstract}

Aedes. Ecologia de vetores.

\begin{abstract}
Two larvae of Aedes scapularis were found in an artificial breeding site, in the Sertaneja County, North of the Paraná State, South Brazil, in the course of routine work for the control of dengue vectors.
\end{abstract}

Aedes. Ecology, vectors.

Aedes scapularis, em contraste com as demais espécies do grupo scapularis, encontra-se amplamente distribuída do Sudoeste dos Estados Unidos ao Norte da Argentina (Forattini ${ }^{2}$, 1965; Arnell ${ }^{1}$, 1976). Esse mosquito é vetor potencial de várias arboviroses, como encefalite eqüina venezuelana e febre amarela, que acometem o homem e animais (Arnell ${ }^{1}, 1976$, Forattini $\left.{ }^{4}, 1995\right)$. Foi constatado como vetor secundário de filariose bancroftiana por Rachou e col. ${ }^{8}$ (1955), no Estado de Santa Catarina. Incriminado como provável vetor na epidemia de encefalite por vírus Rocio no Vale do Ribeira, Sudeste do País (Forattini ${ }^{3}, 1981$ ), teve sua competência vetorial comprovada em laboratório (Mitchell e Forattini $\left.{ }^{7}, 1984\right)$. Aedes scapularis é bem adaptado às transformações antrópicas do ambiente natural. Apresenta forte tendência à endofilia e domiciliação, revestindo-se de grande importância epidemiológica (Forattini ${ }^{4}$, 1995).

As formas imaturas desenvolvem-se em variedade de criadouros temporários ou semipermanentes, sujeitos a regime alternante de inundação e dessecação. São exemplos: as poças de alagamento de rios, terrenos alagadiços, margens de brejos, buracos e depressões no solo, ensolarados ou parcialmente sombreados (Forattini ${ }^{2}, 1965$, Arnell $\left.{ }^{1}, 1976\right)$.

Correspondência para / Correspondence to: Regiane M. T. de Menezes - Laboratório de Entomologia da Superintendência de Controle de Endemias (SUCEN). Rua Paula Souza, 166 - 01027-000 - São Paulo, SP - Brasil - Fax: (055-011) 229.8292

Edição subvencionada pela FAPESP. Processo 95/2290-6.

Recebido em 24.11.1995. Aprovado em 11.12.1995. 
Em 29 de março de 1995, em atividade de rotina da Fundação Nacional de Saúde (FNS), para o controle de vetores da dengue, na localidade de Porto Charles Nauffal, à margem esquerda do rio Paranapanema, Município de Sertaneja $\left(23^{\circ} 01^{\prime} \mathrm{S}\right.$, $\left.50^{\circ} 47^{\prime} \mathrm{W}\right)$, Norte do Estado do Paraná, foram encontradas duas larvas de Aedes scapularis, em criadouro artificial (lata abandonada), entre a rodovia PR - 323 e a mata residual. A identificação da espécie foi confirmada junto à Faculdade de Saúde Pública da USP, em cuja coleção entomológica foi depositada uma larva.

Lane $^{5}$ (1936) havia descrito um criadouro anormal para Aedes scapularis, representado por um pilão, com água limpa e rica em matéria orgânica, encontrado no interior da mata em local sombreado. Lourenço-de-Oliveira $^{6}$ (1986) cita coletas em criadouros artificiais de solo, do tipo vala de drenagem, impressão de pneus e pegadas de animais. No atual encontro observou-se que o criadouro, representado por uma lata de tamanho médio em

\section{REFERÊNCIAS BIBLIOGRÁFICAS}

1. ARNELL, J. H. Mosquito studies (Diptera, Culicidae). XXXIII - A revision of the Scapularis group of Aedes (Ochlerotatus). Contr. Am. Entomol. Inst. , 13: 1-144, 1976.

2. FORATTINI, O. P. Entomologia médica. São Paulo, Ed.USP, 1965. v.2

3. FORATTINI, O.P.; GOMES, A. de C.; SANTOS, J.L.F.; GALATI, E.A.B.; RABELLO, E.X.; NATAL,D. Observações sobre atividade de mosquitos Culicidae em mata residual no Vale do Ribeira, S.Paulo, Brasil. Rev. Saúde Pública, 15: 557-86, 1981.

4. FORATTINI, O.P.; KAKITANI, I.; MASSAD, E.; MARUCCI, D. Studies on mosquitoes (Diptera:Culicidae) and anthropic environment 9- Synanthropy and epidemiological vector role of Aedes scapularis in South-Eastern Brazil. Rev. Saúde Pública, 29: 199-207, 1995.

5. LANE, J. Notas sobre culicídeos de Mato Grosso. Revista do Museu Paulista, 20: 1936. posição vertical, totalmente aberta na face superior, encontrava-se em terreno gramado plano e sem depressões, com outros recipientes que teriam sido descartados junto a um posto fiscal, localizado no $\mathrm{km} 458$ da rodovia citada.

Diante desta constatação, torna-se importante observar se recipientes artificiais tendem a apresentar potencial de criação para Aedes scapularis, a exemplo dos criadouros nos quais a espécie é habitualmente encontrada. Um novo comportamento da espécie abriria perspectivas para investigações.

\section{AGRADECIMENTOS}

Ao Dr. Luiz Roberto Fontes, da Superintendência de Controle de Endemias/ SUCEN, e ao Prof. Dr. Delsio Natal, da Faculdade de Saúde Pública da USP por suas sugestões. À Prof. Dra. Maria Anice M. Sallum, da Faculdade de Saúde Pública da USP, pela confirmação da identificação da espécie.
6. LOURENÇO-DE-OLIVEIRA, R.; HEYDEN, R.; SILVA, T.F. da. Alguns aspectos da ecologia dos mosquitos (Diptera; Culicidae) de uma área de planície (Granjas Calábria), em Jacarepaguá, Rio de Janeiro. V. criadouros. Mem. Inst. Oswaldo Cruz, Rio de Janeiro, 81: 265-71, 1986.

7. MITCHELL,C. J. \& FORATTINI,O. P. Experimental transmission of Rocio encephalitis virus by Aedes scapularis (Diptera: Culicidae) from the epidemic zone in Brazil. J. Med. Entomol. , 21: 34-7, 1984.

8. RACHOU, R.G. ; LIMA, M.M. ; NETO, J.A.F. ; MARTINS, C.M. Inquérito epidemiológico de filariose bancroftiana em uma localidade de Santa Catarina. Como fase preliminar de uma prova profilática. Constatação de transmissão extradomiciliária por um novo vetor, Aedes scapularis. Rev. Bras. Malariol. Doenç. Trop. , 7: 51-70, 1955. 